\title{
XII. Observations on the measurement of an arc of the meridian
}

\section{T. Firminger LL.D.}

To cite this article: T. Firminger LL.D. (1819) XII. Observations on the measurement of an arc of the meridian, Philosophical Magazine Series 1, 54:255, 60-62, DOI:

10.1080/14786441908652185

To link to this article: http://dx.doi.org/10.1080/14786441908652185

册 Published online: 29 Jul 2009.

Submit your article to this journal

Џ Article views: 2

Q View related articles $₫$ 
XII. Olservations on the Measurement of an Arc of the Meridian. By T. Firminger, LL.D.*

$\mathbf{T}_{\text {He measured meridional arcs, in different degrees of latitude, }}$ have not been found to give a ratio of the earth's axis at all consistent either with the theory of a homogeneous ellipsoid of revolution, or with themselves, as deduced by trials of measured arcs in different latitudes : for while some give a ratio nearly the same as Newton has assigned it from theory, others, on the contrary, make the polar axis the longest, or the earth flattened at the equator. Many causes have been assigned as the probable reason of the discrepancy in the results. Colonel Mudge and Captain Kater have attributed the want of agreement to the effect of local attraction : but they differ in toto as to the effect of its influence; or rather, as to the situation of the attracting mass. Colonel Mudge believes the principal effect to take place at Clifton, and Captain Kater at Dunnose. Others again have doubted whether the amplitude of the celestial arc has been correctly obtained; and have supposed, either that the zenith sector. with which ColonelMudge made his observations, might not have beeu exactly placed in the plane of the meridian, or that some error has been committed in the use of it. Mr. Fisher, in a paper just published in the Quarterly Journal of Science and the Arts, endeavours to account for and to rectify these discrepancies, by a supposition " that measured arcs of the meridian are not legitimate measures of the radii of curvature" at the middle point of curvature of thosc arcs. Mr. Fisher seems to have been led into this idea from the consideration of the position of a plumb-line upon a sphere having the same rotation as the earth urged by a centrifugal force: and having calculated the deflections from the centre, at each degree of latitude, he found that the difference, in the deflections, upon the whole arc measured by Colonel Mudge, amounted to exactly that quantity which would reduce the arc to agree.with an excentricity of 229 , to 230 ; from which he concluded that measured arcs are not legitimate measures of the radii of curvature, and " that so long as these measured arcs are cansidered arcs of circles, this correction for deflection will obtain. Mr. Fisher was no doubt led into this mistake from finding that his differences rectified the arcs in those instances in which he applied them ; and too hastily adopted his conclusion, without taking time to examine and consider the problem : for although the arc of a circle and ellipse of the same number of degrees, and of the same radius of curvature, will differ in length; yet this difference is too small (as Dr. Hutton observes, in the account of the formula alluded to by Mr. Fisher,) to sensibly affect the result. There is a circumstance however which has not, that I

* Communicated by the Author. 
knaw of, been noticed by any mathematician, and which will operate, if it amounts to any quantity, as a correction to the observed meridional arc. In an ellipse no two points have the same radius of curvature in the same quadrant : taking, therefore, any part of a meridional line upon the earth's surface (as for instance from Dunnose to Clifton), and eonceiving this as an arc of an ellipse, the radii of curvature, at each extremity of the arc, will not have the same centre; and, therefore, the difference of the zenith distances of any star, taken at the two extremities, will not be a correct measure of the elliptic arc, or rather of an arc of a circle of curvature, which the formula requires.

Let $\mathrm{ABD}$ be a semi-ellipse, $\mathrm{PQ}$ an are; let $\mathrm{PT}, \mathrm{QS}$ be two

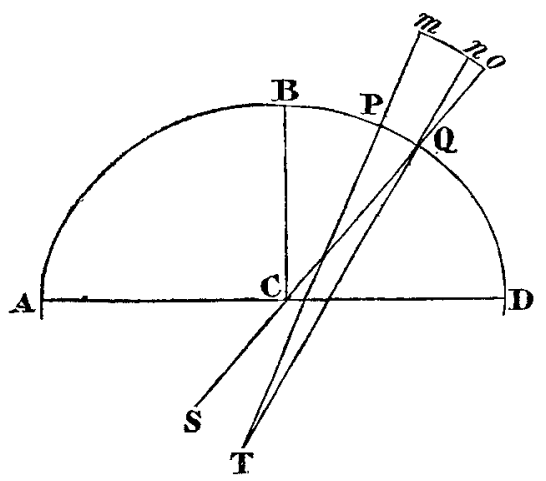

lines drawn perpendicular at $P$ and $Q$, and let $T P$ be a radius of curvature at $\mathrm{P}$, and let $\mathrm{TQ} n$ be drawn: $m$ and $o$ are the zenith points at $P$ and $Q$, supposing $P Q$ to be an arc of the meridian upon the earth's surface; but $m n$ is the measure of $P Q$, which the problem requires; and therefore an arc in the heavens, measured by zenith distances, is not a correct measure of a corresponding arc of curvature on the earth's surface. In the arc measured by Colonel Mudge's sector between Dunnose and Clifton, the angle $n \mathrm{Q} o$, I believe, will be about eight seconds of a degree. If therefore all the stations of Colonel Mudge should: be verified by independent observations, it will not show the result deduced by him to be correct, as the meridional difference of zenith distances of any two places upon the earth's surface, is accurately the difference of latitude of those places. If the angle $n \mathrm{Q} o$ should, upon accurate computation, amount to $8^{\prime \prime}$ upon the whole arc measured between Dunnose and Clifton, the arc between Dunnose and Arbury Hill will require a correction of about $3 \cdot$ " 5 , leaving the results deduced by Colonel Mudge as inconclusive as before, as to the elliptical figure of the meridian. Would it not, therefore, be useful to determine the latitude of 
the several stations lying near the direction of the meridian with a good repeating circle, or other astronomical instrument of great accuracy, upon circumpolar stars above and below the pole? as such observatious would remove all doubt upon the measure of the celestial ares, and might be soon made by any zealous and active observer.**

XIII. Notices respecting New Books.

Transactions of the Geological Society, Vol. V. Part I. 4to. T) pp. 309.

$\mathrm{T}_{\mathrm{HE}}$ following are the contents of the present addition to the valuable Transactions of this Society:

I. On the Island of Salsette. By Stephen Babington, Esq.II. Remarks on the Hills of Badaeson, Szigliget, \&c. in Hungary. By Richard Bright, M.D.-III. Some Observations on a Series of Specimens presented to the Geological Society by the Hon. H. Grey Bennet. By Arthur Aikin, Esq.-IV. Remarks on the Chalk Cliffs in the Neighbourhood of Dover and on the Blue Marle covering the Green Sand near Folkstone, with an Appendix containing some Account of the Chalk Cliffs, \&c. on the Coast of France opposite to Dover. By William Phillips, Esq. - V. Remarks on the Fossils collected by Mr. William Phillips near Dover and Folkstone. By James Parkinson, Esq. -VI. Notes accompanying a Set of Specimens from the Himalay Mountains. By James Fraser, Esq. of Calcutta.-VII. Observations on the Valleys and Watercourses of Shropshire and of Parts of the adjacent Counties. By Arthur Aikin, Esq.VIII. On the Form of the Integrant Molecule of Carbonate of Lime. By Dr. Brewster.-IX. Description of some new Fossil Encrini and Pentacrini lately diseovered in the Neighbourhood of Bristol. By George Cumberland, Esq. - X. On the Limestone Beds on the River Avon near Bristol; with a Description of the Magnesian Beds that repose on their Basset Edges. By George Cumberland, Esq.-XI. On the Strata of the Northern Division of Cambridgeshire. By Francis Lunn, Esq.-XII. Memoir on the Geological Relations of the East of Ireland. By Thomas Weaver, Esq. - XIII. On the Modifications of the Primitive Crystal of the Sulphate of Barytes. By William Phillips, Esq.

* If there should be found at the station at Arbury Hill an error in the measure of the celestial arc amounting to 3 or 4 seconds of a degree, which from the smallness of the quantity may have crept into the account, and also if the angle $n Q 0$ upon the whole arc is found by accurate computation to amount to about $\mathrm{S}^{\prime \prime}$, the whole will agree with an elliptical meridian of $229 \cdot 230$ very nearly, and also agree with deductions dexived from measurements upon other parts of the earth. 